\title{
Patogenicidade de Pratylenchus brachyurus e P. coffeae em Quiabeiro*
}

\author{
Mário M. Inomoto ${ }^{1 * *}$, Rosangela A. Silva ${ }^{1,3}$ \& João P. Pimentel ${ }^{2}$ \\ ${ }^{1}$ Departamento de Entomologia, Fitopatologia e Zoologia Agrícola, Escola Superior de Agricultura "Luiz de Queiroz", \\ Universidade de São Paulo, CEP 13418-900, Piracicaba, SP, fax (19) 3429-4338, e-mail: mminomot@esalq.usp.br; \\ ${ }^{2}$ Laboratório de Virologia Vegetal e Viróides, Universidade Federal Rural do Rio de Janeiro, CEP 23851-970, Seropédica, \\ RJ; ${ }^{3}$ Endereço atual: Ciências Agrárias, Universidade de Várzea Grande, Av. Dom Orlando Chaves, 2655, CEP 78118-000, \\ Várzea Grande, MT
}

(Aceito para publicação em 11/03/2004)

Autor para correspondência: Mário M. Inomoto

INOMOTO, M.M., SILVA, R.A. \& PIMENTEL, J.P. Patogenicidade de Pratylenchus brachyurus e P. coffeae em quiabeiro. Fitopatologia Brasileira 29:551-554. 2004.

\section{RESUMO}

Foram avaliados os efeitos do parasitismo de Pratylenchus brachyurus e de dois isolados de P. coffeae em quiabeiro (Abelmoschus esculentus) em experimento conduzido em casa de vegetação. Algumas mudanças anatômicas induzidas no hospedeiro por $P$. brachyurus foram observadas e registradas em laboratório. O quiabeiro reagiu como bom hospedeiro para $P$. brachyurus e para um dos isolados de $P$. coffeae $\left(\mathrm{K}_{5}\right)$. Entretanto, apenas a primeira espécie reduziu o crescimento da planta. Outro isolado de P. coffeae $\left(\mathrm{M}_{2}\right)$ não se multiplicou em quiabeiro nem afetou o crescimento. Esse fato indicou a possibilidade do quiabeiro ser utilizado no futuro para diferenciação de isolados. Diferentemente das relações parasito-hospedeiro envolvendo Pratylenchus spp., $P$. brachyurus não causou lesões radiculares delimitadas, mas grandes áreas necrosadas. Sintomas iniciais foram observados em quiabeiro dez e 15 dias após a inoculação com $P$. brachyurus, não se verificando a presença do parasito no estelo de raízes infetadas.

Palavras-chave adicionais: Abelmoschus esculentus, nematóide das lesões, relações parasito-hospedeiro, variabilidade.

\section{ABSTRACT}

Pathogenicity of Pratylenchus brachyurus and P. coffeae in okra The effect of Pratylenchus brachyurus and P. coffeae on the growth of okra (Abelmoschus esculentus) was evaluated in a greenhouse experiment. The anatomical changes caused by $P$. brachyurus were studied under laboratory conditions. Okra was a good host for $P$. brachyurus and one isolate of $P$. coffeae $\left(\mathrm{K}_{5}\right)$, but only the former decreased its growth. The other isolate of $P$. coffeae used $\left(\mathrm{M}_{2}\right)$ did not multiply on nor damage okra, so this plant can be used to differentiate both isolates. In contrast to typical Pratylenchus spp. host plant relationships, P. brachyurus did not cause welldelimited root lesions, but large extensions of decayed tissues. Necrosis in okra roots was observed ten days after inoculation, but $P$. brachyurus was not found in the stele of infected roots 15 days after inoculation.
O quiabeiro [Abelmoschus esculentus (L.) Moench], planta pertencente à família Malvaceae, é de porte arbustivo e ereto, com altura entre 0,5 e $3 \mathrm{~m}$. Tem sido cultivado há milhares de anos pelos egípcios e outros povos; foi introduzido nas Américas pelos povos africanos (Minami \& Zanin, 1984). Atualmente é utilizado como olerícola, pelo fruto palatável, e ainda para fornecimento de fibras e produção de óleo comestível. O Brasil encontra-se entre os cinco maiores produtores mundiais de quiabo, sendo o estado do Rio de Janeiro o principal produtor. Os nematóides das galhas (Meloidogyne spp.) são considerados importantes patógenos dessa olerícola, entretanto a importância dos nematóides das lesões (Pratylenchus spp.) é pouco conhecida. Duas espécies, $P$. brachyurus (Godfrey) Filipjev \& Schuurmans Stekhoven e $P$. pseudopratensis Seinhorst, foram relatadas em associação com o quiabeiro no Brasil (Café Filho \& Huang, 1988). Segundo observação dos autores, P. brachyurus é

\footnotetext{
*Financiado pela FAPESP (processo no. 01/11264-1)
}

**Bolsista CNPq freqüentemente associado ao quiabeiro no Rio de Janeiro, causando pronunciada incidência de raízes necrosadas.

A suscetibilidade do quiabeiro a $P$. brachyurus já foi estudada anteriormente. Experimento em casa de vegetação, realizado no Brasil (Charchar \& Huang, 1981), em que foram estudadas 19 olerícolas quanto à reprodução de $P$. brachyurus, mostrou que a população do nematóide aumentou 3,2 vezes em quiabeiro cv. Piranema, três meses após inoculação, enquanto nas melhores hospedeiras, tomateiro (Lycopersicon esculentum Mill.) cv. Santa Cruz Kada e meloeiro (Cucumis melo L.), o aumento foi de 54 vezes. Em experimento semelhante realizado na Nigéria, com 30 diferentes olerícolas, o quiabeiro, a berinjela (Solanum melogena L.) e a pimenteira (Capsicum frutescens L.) foram as melhores hospedeiras de $P$. brachyurus, propiciando aumentos populacionais correspondentes a 30 vezes, 75 dias após a inoculação (Khan, 1992). Segundo Machado \& Inomoto (2001), dentre 18 olerícolas testadas em casa de vegetação, o quiabeiro cv. Santa Cruz foi um dos melhores hospedeiros de 
um isolado de $P$. brachyurus, coletado no município de Seropédica, RJ, aumentando a população do nematóide 15vezes, 65 dias após a inoculação.

Não há registro da ocorrência de Pratylenchus coffeae (Zimmermann) Filipjev \& Schuurmans Stekhoven em associação com quiabeiro. Entretanto, Silva \& Inomoto (2002), estudando a suscetibilidade do quiabeiro e de outras hortaliças em relação a dois isolados dessa espécie, um de raízes de cafeeiro (Coffea arabica L.) oriundas de Marília, SP, e outro de raízes de Aglaonema sp. coletadas no município do Rio de Janeiro, verificaram que a variação populacional do isolado de Marília em quiabeiro foi 6,16, superior ao obtido em cafeeiro, que foi 1,02 , sendo este o hospedeiro típico da espécie. Por outro lado, a população do isolado Rio de Janeiro diminuiu em quiabeiro, à semelhança do ocorrido em cravo-de-defunto (Tagetes patula L.), que é considerado imune a P. coffeae. Assim, foi possível concluir que o quiabeiro deve ser pesquisado como diferenciador de isolados de $P$. coffeae.

A presença de $P$. brachyurus associado à intensa necrose radicular do quiabeiro no Rio de Janeiro é indicativo do potencial patogênico desse nematóide. De acordo com a literatura, provavelmente esse nematóide causa perdas à cultura do quiabeiro na Nigéria, pois há relato naquele País do uso de matéria orgânica com a finalidade de controlar $P$. brachyurus e aumentar o crescimento da cultivar Long Green (Khan, 1994). Não há, até o momento, nenhum trabalho demonstrando o efeito de $P$. brachyurus ou $P$. coffeae no desenvolvimento do quiabeiro, bem como descrição dos sintomas em raízes.

O objetivo do presente trabalho foi estudar o efeito dos nematóides das lesões sobre o crescimento de plantas de quiabeiro cv. Esmeralda, uma das principais cultivares utilizadas atualmente no Brasil. Neste experimento, feito em casa de vegetação, estudaram-se $P$. brachyurus e dois isolados de $P$. coffeae, tomando-se separadamente observações dos sintomas causados por $P$. brachyurus nas raízes.

Foi utilizado o isolado $\mathrm{Pb}_{20}$ de $P$. brachyurus, obtido de raízes de quiabeiro no município de Seropédica, RJ, e dois isolados de $P$. coffeae, $\mathrm{K}_{5}$ (isolado Marília, $\mathrm{SP}$ ) e $\mathrm{M}_{2}$ (isolado Rio de Janeiro, RJ). Eram isolados muito virulentos às plantas de origem, pois as raízes de onde foram obtidos apresentavam pronunciadas necroses. Os três isolados foram mantidos em calos de alfafa (Medicago sativa L.), segundo a metodologia de Riedel et al. (1973), e os inóculos obtidos pela extração dos espécimes presentes nos calos por meio do método de Baermann modificado para recipiente raso (Southey, 1986).

Plântulas de quiabeiro foram obtidas a partir de sementes da cv. Esmeralda, adquiridas no comércio e plantadas em sementeira de isopor contendo substrato (constituído por uma parte de solo para uma de areia de granulometria média) tratado com brometo de metila (150 $\mathrm{ml} \mathrm{de} \mathrm{CH}_{3} \mathrm{Br}$ por $1.000 \mathrm{l} \mathrm{de}$ solo). As plântulas foram transferidas para vasos plásticos, de 2,1 1 de capacidade, considerando-se a razão de uma por vaso, que continha 1,8 l do substrato. A inoculação foi efetuada quando as plântulas estavam com a primeira folha verdadeira completamente expandida, o que ocorreu 21 dias após a semeadura, por incorporação de $3 \mathrm{ml}$ do inóculo, contendo
1.000 nematóides/ $\mathrm{ml}$, em dois orifícios de $2 \mathrm{~cm}$ de profundidade, feitos no substrato a $1 \mathrm{~cm}$ do colo da plântula. Antes da inoculação, cada orifício foi forrado com lenço de papel, para ser evitada perda de inóculo por lixiviação. O delineamento experimental utilizado foi do tipo inteiramente casualizado, com quatro tratamentos e dez repetições. Os tratamentos constaram de inoculações de plantas com espécimes dos nematóides nas seguintes proporções: 1$) 3.000 P$. brachyurus $\left(\mathrm{Pb}_{20}\right)$; 2) 3.000 P. coffeae isolado Marília $\left(\mathrm{K}_{5}\right)$; 3$) 3.000$ P. coffeae isolado Rio de Janeiro $\left(\mathrm{M}_{2}\right)$; 4) testemunhas não inoculadas.

Os quiabeiros foram mantidos durante o período experimental em casa de vegetação e a avaliação feita 107 dias após a inoculação. Após a colheita, a parte aérea das plantas foi seca em estufa a $70{ }^{\circ} \mathrm{C}$. As raízes foram pesadas para obtenção da massa fresca e, logo a seguir, quatro de cada tratamento foram processadas para extração dos nematóides pelo método de Coolen \& D’Herde (1972). Os espécimes presentes no substrato foram extraídos pelo método de Jenkins (1964). Foi feita a contagem dos nematóides em microscópio óptico, com auxílio de lâmina de Peters, para obtenção da variação populacional ou fator de reprodução, estabelecido pela relação entre a população final e a população inicial (FR = Pf/ Pi) em cada parcela. Os dados de altura da parte aérea, massa fresca das raízes e massa seca da parte aérea foram submetidos à análise de variância e as médias comparadas pelo teste de Tukey a $5 \%$ de significância, usando-se o "software" Sanest (Ciagri e Departamento de Matemática e Estatística, ESALQ/USP, Piracicaba, SP).

Para caracterizar os sintomas causados por $P$. brachyurus $\left(\mathrm{Pb}_{20}\right)$ em raízes de quiabeiro, as raízes do experimento foram observadas e fotografadas. Além disso, com o objetivo de estudar as modificações iniciais causadas pelo nematóide, plântulas de quiabeiro cv. Esmeralda foram obtidas pelo mesmo método anterior. Dentro da própria sementeira, 18 plântulas foram individualmente inoculadas com cerca de 100 $P$. brachyurus quando estavam com a primeira folha verdadeira completamente expandida e 18 permaneceram livres do nematóide. As avaliações foram feitas cinco, dez e 15 dias após a inoculação. Em cada dia, seis plântulas inoculadas e seis não inoculadas foram retiradas das células da sementeira e cuidadosamente lavadas em água corrente. Após exame visual, as raízes exibindo sintomas necróticos foram fotografadas em estereomicroscópio. Em seguida, foram diafanizadas com hipoclorito de sódio e coradas com fucsina ácida (Byrd et al., 1984), sendo então novamente observadas ao estereomicroscópio, para contagem do número de nematóides e novas fotografias. As raízes não infetadas também foram diafanizadas e coradas para confirmar a ausência do nematóide no interior.

Os quiabeiros inoculados com 3.000 P. brachyurus apresentaram menor desenvolvimento que quiabeiros não inoculados (Tabela 1) e as raízes ficaram com grandes áreas escurecidas (Figuras 1 e 2). Não foi observada nítida alternância de tecido claro e escuro, ou seja, não se verificaram lesões bem delimitadas e discerníveis do tecido sadio. Menores e com grandes áreas não funcionais, as raízes infetadas por $P$. 
Patogenicidade de Pratylenchus brachyurus e P. coffeae em quiabeiro

TABELA 1 - Efeito de Pratylenchus brachyurus (isolado $\mathrm{Pb}_{20}$ ) e de dois isolados de $P$. coffeae $\left(\mathrm{K}_{5}\right.$ e $\mathrm{M}_{2}$ ) no crescimento de plantas de quiabeiro (Abelmoschus esculentus) cv. Esmeralda, 107 dias após a inoculação

\begin{tabular}{|c|c|c|c|c|c|}
\hline Tratamento & $\begin{array}{l}\text { Massa fresca } \\
\text { das raízes }(\mathrm{g})^{1}\end{array}$ & $\begin{array}{c}\text { Massa seca do caule + } \\
\text { folhas }(\mathrm{g})^{1}\end{array}$ & $\begin{array}{l}\text { Massa seca dos } \\
\text { frutos }(\mathrm{g})^{1}\end{array}$ & $\begin{array}{l}\text { Massa seca da paite aerea } \\
(\text { caule }+ \text { folhas + frutos) }(g)\end{array}$ & $\mathbf{P f} / \mathbf{P i}^{2}$ \\
\hline Pratylenchus brachyurus $\left(\mathrm{Pb}_{20}\right)$ & $16,6 \mathrm{~b}$ & $4,4 \mathrm{~b}$ & $4,5 \mathrm{~b}$ & $8,9 \mathrm{~b}$ & 7,88 \\
\hline P. coffeae Marília $\left(\mathrm{K}_{5}\right)$ & $25,5 \mathrm{ab}$ & $6,1 \mathrm{ab}$ & $8,2 \mathrm{a}$ & $14,3 \mathrm{a}$ & 2,93 \\
\hline P. coffeae Rio de Janeiro $\left(\mathrm{M}_{2}\right)$ & $28,0 \mathrm{a}$ & $7,1 \mathrm{a}$ & $8,2 \mathrm{a}$ & $15,3 \mathrm{a}$ & 0,44 \\
\hline Testemunha & $30,0 \mathrm{a}$ & $7,3 \mathrm{a}$ & $8,2 \mathrm{a}$ & $15,5 \mathrm{a}$ & - \\
\hline
\end{tabular}

${ }^{1}$ Cada valor é a média de dez repetições; médias seguidas de mesma letra na coluna não diferem entre si pelo teste de Tukey a 5 \% de probabilidade. ${ }^{2}$ Cada valor é a média de quatro repetições.

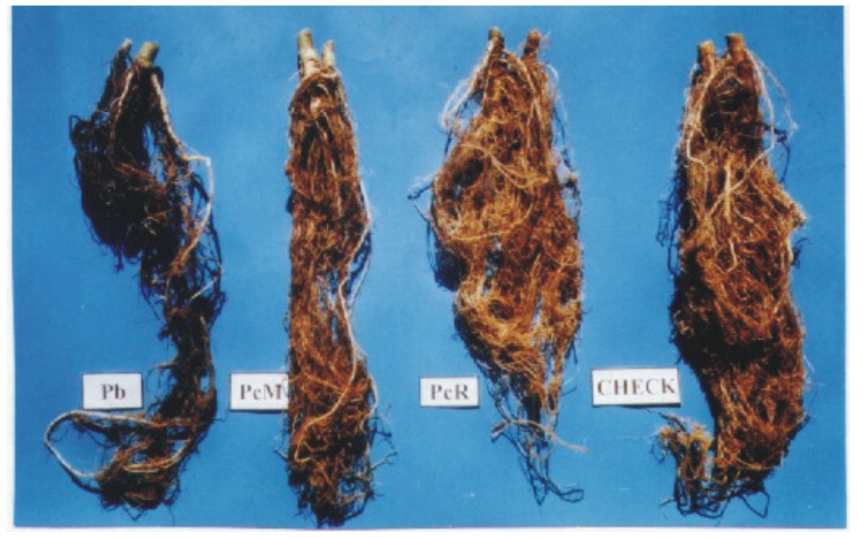

FIG. 1 - Raízes de quiabeiro (Abelmoschus esculentus) infetadas por Pratylenchus brachyurus $\left(\mathrm{Pb}=\right.$ isolado $\left.\mathrm{Pb}_{20}\right), P$. coffeae $(\mathrm{PcM}=$ isolado $\mathrm{K}_{5}$, PcR = isolado $\mathrm{M}_{2}$ ) e raiz não infetada (check = testemunha), 107 dias após a inoculação.

brachyurus eram deficientes, resultando em menor acúmulo de matéria seca na parte aérea. Tal resultado comprovou que o quiabeiro é suscetível a $P$. brachyurus, em concordância com trabalhos anteriores (Khan, 1992; Machado \& Inomoto, 2001), e ainda mostrou que $P$. brachyurus causa danos severos, em concordância com as observações de campo. Por outro lado, nenhum dos dois isolados de $P$. coffeae afetou o crescimento dos quiabeiros. As raízes das plantas infetadas com o isolado Marília $\left(\mathrm{K}_{5}\right)$ apresentavam regiões escurecidas, mas em muito menor extensão que as infetadas por $P$. brachyurus. Tal efeito não foi suficiente para afetar significativamente o crescimento do quiabeiro, nas condições experimentais adotadas. Já o outro isolado de $P$. coffeae $\left(\mathrm{M}_{2}\right)$ não causou nenhuma alteração visível nas raízes do quiabeiro, o que pode estar relacionado à diminuição populacional desse nematóide $(F R=0,44)$ após 107 dias da inoculação, resultado já esperado, tendo em vista relato anterior que demonstrou que outra cultivar de quiabo (Santa Cruz IAC-47) era hospedeira favorável de $\mathrm{K}_{5}$, mas desfavorável de $\mathrm{M}_{2}$ (Silva \& Inomoto, 2002). Isto é uma indicação de que o quiabeiro pode ser utilizado para diferenciar isolados de P. coffeae.

Cinco dias após a inoculação, não se observaram necroses radiculares nos quiabeiros infetados com $100 P$. brachyurus. Contaram-se em média 22 espécimes por raiz nas

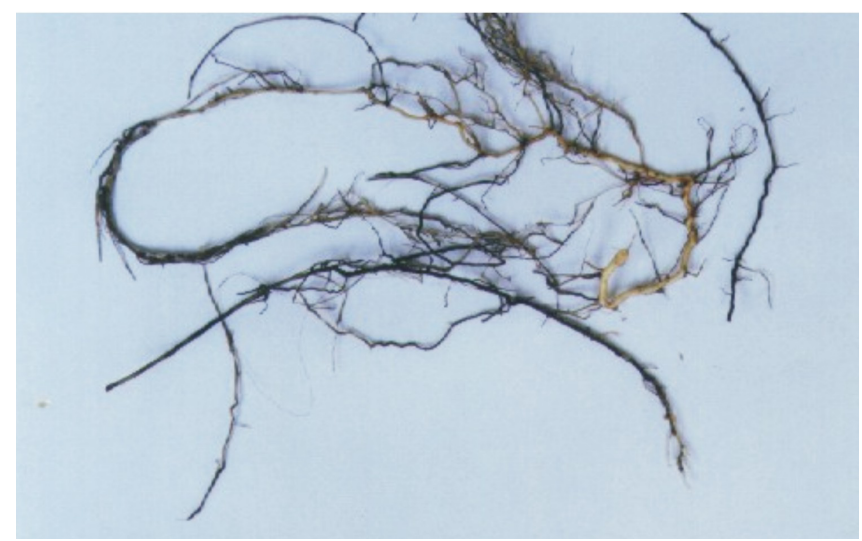

FIG. 2 - Vista geral de raízes de quiabeiro (Abelmoschus esculentus) infetadas por Pratylenchus brachyurus, notando-se extensas áreas com escurecimento.

plântulas infetadas. Dez dias após a inoculação, trechos necróticos alongados foram observados nas raízes, onde se contaram em média 46 espécimes por raiz. Quinze dias após a inoculação, as necroses tornaram-se muito evidentes e contaram-se em média 48 espécimes por raiz. Esses valores referem-se apenas aos adultos e juvenis, pois os ovos não foram contados. Tais resultados indicam que cerca de metade dos nematóides usados na inoculação logrou invadir a raiz do quiabeiro.

Necroses e nematóides não foram observados nas raízes das plantas não inoculadas, em nenhuma das datas de avaliação. Apesar dessas plantas não terem sido cultivadas em condições assépticas, duas razões levam à conclusão que os sintomas observados foram resultado direto da atividade de $P$. brachyurus: 1) o curto tempo entre a inoculação e o aparecimento das necroses; 2) o tratamento do substrato com brometo de metila, que embora não seja capaz de esterilizar o solo reduz consideravelmente a quantidade de microrganismos porventura presentes.

Conclui-se que $P$. brachyurus é prejudicial ao quiabeiro por causar escurecimento e necrose em raízes infetadas, poucos dias após a inoculação. Tal efeito resulta em reduzido desenvolvimento da parte aérea. Os dois isolados de $P$. coffeae testados não foram patogênicos ao quiabeiro, mas com diferenças epidemiológicas importantes entre si. Um $\left(\mathrm{K}_{5}\right)$ 
aumentou populacionalmente e causou destruição de pequenas áreas das raízes, visíveis a olho nu, embora sem afetar o crescimento da planta; o outro $\left(\mathrm{M}_{2}\right)$ teve a população reduzida durante o período experimental de 107 dias.

\section{REFERÊNCIAS BIBLIOGRÁFICAS}

BYRD JR., D.W., KIRKPATRICK, T. \& BARKER, K.R. An improved technique for clearing and staining plant tissue for detection of nematodes. Journal of Nematology 15:142-143. 1983.

CAFÉ FILHO, A.C. \& HUANG, C.S. Nematóides do gênero Pratylenchus no Brasil. Fitopatologia Brasileira 13:232-235. 1988.

CHARCHAR, J.M. \& HUANG, C.S. Círculo de hospedeiras de Pratylenchus brachyurus II - hortaliças. Fitopatologia Brasileira 6:6772. 1981.

COOLEN, W.A. \& D’HERDE, C.J. A Method for the Quantitative Extraction of Nematodes from Plant Tissue. Ghent, State Nematology and Entomology Research Station, 1972.

JENKINS, W.R. A rapid centrifugal-flotation technique for separating nematodes from soil. Plant Disease Reporter 48:692. 1964.

KHAN, F.A. Multiplication rates of Pratylenchus brachyurus in some vegetable crops in northern Nigeria. Crop Protection 11:127129. 1992.

KHAN, F.A. Effect of soil organic amendments on the development of Pratylenchus brachyurus and growth and yield of okra. Afro Asian Journal of Nematology 4:84-87. 1994.

MACHADO, A.C.Z. \& INOMOTO, M.M. Host status of eighteen vegetable crops for Pratylenchus brachyurus. Nematropica 31:257263. 2001.

MINAMI, K. \& ZANIN, A.C.W. Cultura do Quiabo. Piracicaba, Centro Acadêmico Luiz de Queiroz, 1984.

RIEDEL, R.M., FOSTER, J.G. \& MAI, W.F. A simplified medium for monoxenic culture of Pratylenchus penetrans and Ditylenchus dipsaci. Journal of Nematology 5:71-72. 1973.

SILVA, R.A. \& INOMOTO, M.M. Host-range characterization of two Pratylenchus coffeae isolates from Brazil. Journal of Nematology 34:135-139. 2002.

SOUTHEY, J. F. Laboratory Methods for Work with Plant and Soil Nematodes. London. Her Majesty’s Stationery Office. 1986. 